\title{
Article
}

\section{Reclaiming the humanity in personality Disorder.}

Mckeown, Mick, Haigh, Kevin and Wright, Karen Margaret

Available at http://clok.uclan.ac.uk/81/

Mckeown, Mick ORCID: 0000-0003-0235-1923, Haigh, Kevin and Wright, Karen Margaret ORCID: 0000-0003-0693-7294 (2007) Reclaiming the humanity in personality Disorder. International Journal of Mental Health Nursing, 16 (4). pp. 236-246. ISSN 1447-0349

It is advisable to refer to the publisher's version if you intend to cite from the work. http://dx.doi.org/10.1111/j.1447-0349.2007.00480.x

For more information about UCLan's research in this area go to

http://www.uclan.ac.uk/researchgroups/ and search for < name of research Group>.

For information about Research generally at UCLan please go to http://www.uclan.ac.uk/research/

All outputs in CLoK are protected by Intellectual Property Rights law, including Copyright law. Copyright, IPR and Moral Rights for the works on this site are retained by the individual authors and/or other copyright owners. Terms and conditions for use of this material are defined in the policies page.

\section{CLoK}

Central Lancashire online Knowledge www.clok.uclan.ac.uk

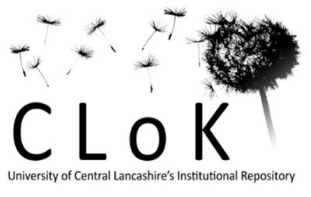




\section{Article}

\section{Reclaiming the humanity in personality Disorder}

Wright, Karen, Haigh, Kevin and McKeown, Mick

Available at http://clok.uclan.ac.uk/6247/

Wright, Karen, Haigh, Kevin and McKeown, Mick (2007) Reclaiming the humanity in personality

Disorder. International Journal of Mental Health Nursing, 16 (4). pp. 236-246. ISSN 1447-0349

It is advisable to refer to the publisher's version if you intend to cite from the work. http://dx.doi.org/10.1111/j.1447-0349.2007.00480.x

For more information about UCLan's research in this area go to http://www.uclan.ac.uk/researchgroups/ and search for <name of research Group>.

For information about Research generally at UCLan please go to http://www.uclan.ac.uk/research/

All outputs in CLoK are protected by Intellectual Property Rights law, including Copyright law. Copyright, IPR and Moral Rights for the works on this site are retained by the individual authors and/or other copyright owners. Terms and conditions for use of this material are defined in the http://clok.uclan.ac.uk/policies/ 
Karen Wright, Kevin Haigh \& Mick McKeown. Reclaiming the Humanity in

Personality Disorder. International Journal of Mental Health Nursing

\begin{abstract}
This paper provides a commentary upon the nursing care of individuals diagnosed with personality disorder and associated education courses. The discussion focuses upon recent policy trends in the UK as a point of departure. This policy discourse is critical of mainstream mental health services in previously operating to exclude such individuals. One of the consequences has been a recent growth in interest in relevant training courses, many of which devote significant attention to staff attitudes regarding this client group. Various previous researchers and commentators have remarked upon the implications for practice of a perceived negative attitude amongst care staff.
\end{abstract}

We reflect upon our own anecdotal experience of developing and delivering new university based courses for practitioners working in the field of personality disorder to offer a particular critique of the UK context in which this policy, training and practice is framed. Social constructionist theories are drawn on to offer insights into public and practitioner discourse and the possible effects on therapeutic relationships. The available discourse constructs individuals with a diagnosis of personality disorder as essentially different from other people. We argue that staff training and practice development initiatives are likely to be more successful if such discourse is challenged, and attempts are made in therapeutic encounters to recognise shared characteristics and positive attributes as much as perceived difference and negative attributes. We refer to this as a re-engagement with common humanity. Despite the singular national context the discursive themes explored are not necessarily restricted to the UK. 
Key words: Personality disorder, training, social construction, policy, self awareness

Introduction

Contemporary UK health policy urges mainstream mental health services to be more responsive to the needs of individuals with a diagnosis of personality disorder (National Institute Mental Health England/Department of Health NIMHE/DH $2003 a, 2003 b)$. In support of these aims various training and education courses have been, or are being, developed to better prepare practitioners. We have been involved in the delivery of relevant Certificate level to Masters level courses in the North West of England, and our experiences in this regard inform this paper.

We also draw upon social constructionist theories for analysis of relevant social processes and to inform our conclusions for a way forward in practitioner education. Social constructionist ideas are critical of established or taken for granted western scientific and governmental institutions and practices, especially positivism, and the power of language is emphasised in the construction of social reality. The complex ways in which people talk and make sense of the world are seen to be inextricably linked to action, giving rise to Foucault's (1972) phraseology of discursive practices. A number of commentators have suggested that constructionist theories are very much appropriate for understanding the discourse and practices of health care contexts, and addressing mental health specifically (see Fox 1993; Holmes 2001; Mason \& Mercer 1998; Parker et al 1995; Stainton Rogers 1991; Willig 1999). An important concept in this regard which we will return to in this paper is the notion of 'otherness'. 
Individuals diagnosed with personality disorder exemplify the notion of the unpopular patient, provoking a range of negative reactions which have been remarked upon in the literature over a significant amount of time (Bowers 2002; Blackburn 1988; Hinshelwood 1999; Main 1957; Pilgrim 2001). A dimension of this is the moral judgements that are brought to bear in the appraisal of people and their behaviour. Staff viewpoints are often undifferentiated from powerful lay discourses that emphasise moral rather than clinical issues. When clinical discourse becomes laced with morality tales and value judgments, individuals are cast as undeserving of care, and can fail to achieve the status of patients in the same way as others with different diagnostic labels. Such social processes can be seen as part of a broader construction of 'otherness' and assist in explaining the sorts of interpersonal reactions that can arise. This can deflect attention from attempting to understand why people might behave in upsetting or anti-social ways, closing off one possible avenue for providing useful therapeutic intervention. A case can be made for developing more considered and insightful analyses of the notion of personality disorder.

Arguably, one effect of all of this is to skew the focus of staff training and education initiatives. It would be desirable to focus, without distraction, upon acquisition of skills and knowledge to best meet the actual needs of this client group. However, most training has firstly to attempt to engage with attitudes before progressing towards more practical concerns. One way out of this is to directly challenge constructions of 'otherness' and re-establish supportive and caring approaches grounded in purposeful, therapeutic inter-personal relationships.

This argument will be developed by first highlighting relevant UK mental health policy. We then turn to look in more detail at the social representations of personality disorder available for people to draw upon, and suggest links between these, remarked-upon inadequacies in services and difficulties in therapeutic 
encounters. These themes are then explored in relation to experiences of involvement in practitioner training initiatives that have arisen as a consequence of the aforementioned policy guidance. The central importance of discourse that depicts this client group as essentially and fundamentally different, or 'other', is focused upon to suggest that it is important to critically engage with these notions so that progress can be made in improving affairs in line with the policy aspiration that services are no longer exclusionary. We offer one suggested solution, which is to raise practitioners' consciousness of common human characteristics and positive attributes rather than solely tune into perceived differences and negative attributes in therapeutic encounters with this client group. Arguably, the discursive themes explored here are of wider relevance than the UK context in which our analysis and reflections are grounded.

\section{Policy Background}

The notion of personality disorder is prominent in both of the diagnostic systems, DSM (APA 2000) and ICD (WHO 1992) currently favoured across western psychiatric services. Distinct challenges in how to organise services to best meet relevant care and treatment needs, including the vexed question of treatability for some individuals, have been fairly common across different national jurisdictions.

In 1999, when the UK government announced plans to introduce legislation in England and Wales for compulsory detention of people with dangerous severe personality disorders [DSPD], speculation soared within the media and public services. The term 'dangerous severe personality disorder', which is used as both a noun and an adjective, has no universally accepted definition. The Royal College of Psychiatrists suggest that DSPD should be characterised by "gross societal disturbance" as well as "gross severity of personality disorder within the flamboyant group and a personality disorder in at least one other cluster also' (Royal College of 
Psychiatrists 1999, p.11). Diagnosis is highly controversial and issues of reliability and validity exist since diagnosis is frequently made by interview and disagreement may be common. A postal survey revealed that such diagnoses were rarely based upon structured diagnostic instruments (Milton 2000). The high prevalence of substance misuse and co-morbidity further complicates presentations and decisions tend to be made in respect of the individual's perceived risk to public safety rather than any specificity of mental disorder (Chiswick 2001; Morrall 2000).

In policy terms 'personality disorder', already cloaked in pejorative and disparaging connotations was now inextricably linked with terminology which inferred that the public at large were implicitly vulnerable to a group of individuals for whom there seemed to be no solution other than containment. Within months, the White paper 'Reforming the Mental Health Act' (DH 2000), was published which contained proposals relating to high-risk patients. The subsequent draftings and the eventual failure to deliver comprehensive reform of the Act is indicative of the lack of agreement that surrounds the biggest shake up of Mental Health legislation in England and Wales for 20 years. At a time when mental health services are asked to provide care and treatment for the client with a personality disorder we have also to acknowledge that policy is shifting to increasingly enable compulsory detention. Ironically, this provides for an equal standing in this regard with individuals diagnosed with mental illnesses such as schizophrenia. In the past, the belief that personality disorder is untreatable has been deeply ingrained and this has been used as a reason for not deploying legislative powers and, in effect, excluding individuals with personality disorder from general mental health services. The publication of 'Personality Disorder: No Longer A Diagnosis of Exclusion' (NIMHE/ DH 2003a) reflects this fact and has been instrumental in illuminating the needs of service-users, services, carers and education/training providers. 


\section{Representations of Personality Disorder}

The policy ambivalence, simultaneously promoting containment and care, is mirrored in mass media representations of personality disorder. All mental health service users are subject to stigmatising and stereotypical representation and constructions of otherness, whether in the discourse of the lay public, the pages of the print media or on TV and cinema screens. Quite often these accounts fail to differentiate between the various medical categories of mental disorder, with terms such as psychotic and psychopathic used interchangeably in a context of public fear of violent madness. Various commentators have noted the range of media depictions of the mentally unwell, with individuals described as monsters, homicidal maniacs, narcissistic parasites, raving mad, bad, or absolutely evil. Different stories suggest a public reaction ranging from horror to sympathy, with various stops along the way through ridicule and titillation. Inevitably the media prescription for policy is for containment: these people are either dangerous and in need of secure detention, or they present a risk to themselves and are in need of the emotional security of asylum (see Gleeson 1991; Hyler et al 1991; McKeown \& Clancy 1995). This fits with a perception that many of those individuals considered violent and criminal should rationally be incarcerated as a moral and justifiable action to protect a vulnerable, and blameless society.

A recent UK national newspaper featured experiences at a high-security prison. Various individuals spoke of the identity issues at stake in receiving the status of dangerous and severe personality disorder:

'At the end of the day, all of us sitting here are monsters, whether we're armed robbers, child molesters, or killers - we're monsters' 
'You know when things are getting bad when you're released from a stretch and you go back to your own estate and the hard men you used to know there seem scared, when they treat you like a psycho' (anonymous interviewees, quoted in Rose 2005; p.21)

In the past, personality-disordered prisoners who were incarcerated for their crimes but were not provided with treatment have been released only to re-offend, further contributing to public and government demands for indefinite detention for some. Unfortunately, the term 'personality disorder' often becomes inextricably linked with concepts of dangerousness and evil in lay consciousness.

\section{The Construction of Difference}

The available media representations of madness and personality disorder are sustained within a broader set of social constructs which expose a dynamic relationship between idealised selfhood and denigrated otherness. The anthropologist Clifford Geertz (1977) articulated a succinct definition of the self in modern society as a:

...bounded, unique, more or less integrated motivational and cognitive universe, a dynamic centre of awareness, emotion, judgement and action, organized into a distinctive whole and set contrastively against other such wholes and against a social and natural background.... (Clifford Geertz 1977; p.483)

This particularly western conceptualisation of the self has proven to be very much compatible with the prevailing hegemony of science and capitalism and has become increasingly dominant and prominent in psychologised and lay discourse. (Ingleby 1985; Rose 1990) This notion of the self is the archetypal subject of much 
counselling and psychotherapy (Venn 1984); which can, indeed, be described as self-celebratory (Sampson 1993). In human interaction, this version of the self can be seen, at least in part, to take shape via its relationship to its antithesis - that which encapsulates a sense of 'otherness'. Young (1999) has argued that this construction of difference is almost inevitably accompanied by a demonisation of the 'other'. Otherness in the context of stigmatised or demonised groups suggests some essential denial of common attributes or shared characteristics, it is all or nothing: it casts the other as essentially different: as less than human.

The diagnosis and institutional containment of different versions of personality disorder further establishes the behaviour of the individuals concerned as 'other'. These diagnostic acts operate to restore order to the prevailing symbolic framework, at least in part by reinforcing what is deemed to be normal, or morally appropriate. This is enacted in a process of making clear the boundary between this normality and what is not: that which is different, and 'other'. Hence, categories of personality disorder, especially the extreme variants, are presented as completely distinct from a prevailing view of what constitutes normal and common humanity. These disordered 'selves' are not like 'ourselves', and explicit knowledge that this is so, is comforting, and allays anxiety about extremes of behaviour and the nature of ourselves. Indeed, one clear function of the construction of difference is that it allows for the projection of unwanted parts of the ideal self into the denigrated other (Timmi 1996; Dalal 2001). Awareness of such processes ought to enable us to deconstruct our notions of self and personality disorder (as an exemplar of otherness) and move towards reclaiming the common humanity in individuals so labelled. ${ }^{1}$

\footnotetext{
${ }^{1}$ It is not our intention here to propose an equally essentialist common humanity in juxtaposition to the problematic otherness. Rather we suggest that the construction of otherness functions as it were to obliterate any possibility of recognising shared human features and characteristics in such individuals. It is this re-engagement with the person and recognition that we will have commonalities and, further, that no
} 
Of course, the notion of otherness in mental health, other health contexts, or wider society for that matter, is not restricted to discursive practices surrounding personality disorder and numerous scholars have utilised social constructionist theories to illuminate this (Canales 2000; Holmes 2003; Hamilton \& Manias 2006; Johnson et al 2004; Maccallum 2002; Peternelj-Taylor 2004; Warner \& Gabe 2004). Constructions of otherness arguably pervade the mental health system, with many other kinds of patients, members of population groups or diagnostic groups cast as 'other' by virtue of the formal and informal categories used to define them, or even to simply refer to them (Crowe 2000; Maccallum 2002). Prime examples of such discourse construct difference relating to categories of ethnicity, gender, and age: Utilising constructionist theory and associated methodologies, studies of our own have addressed social constructions of mental health and race (Stowell-Smith \& McKeown 1999a), psychopathy and race (Stowell-Smith \& McKeown 1999a), gender and challenging behaviour (McKeown et al 2003) and risk in mental health services (McKeown et al 1999).

The consequences of such constructions of difference are keenly felt by service users with diagnoses of personality disorder:

We get stigma from medical professionals - many older psychiatrists still live with the PD as a dustbin diagnosis - we can't get them better therefore let's give them a label that means they are awkward then we can kick them out. Many psych nurses have the same impressions as they are not trained in PD's so they have no idea how to handle us. They accuse us of 'acting out'

diagnostic label ought to blind us to the uniqueness of individuals which is at stake in our argument. 
when we are doing anything that they do not understand .. as this is some psychobabble word that they have heard but do not understand truly. (Anderson 2004)

Service user narratives can also suggest openings for care and treatment strategies, and can focus upon the relevance of social and developmental factors in case histories. A personal account by Caroline Hopkinson (2002) suggests that her diagnosis of personality disorder was, in her view, a consequence of childhood experiences, specifically witnessing her father beat her mother, who was herself a heavy drinker. Such reflections have the potential to initiate engagement with psychologically or psychodynamically informed therapeutic understandings and interventions. Conversely, however, practitioner reliance upon powerful constructions of difference and otherness can lead to distinct therapeutic pessimism and inertia, and may, at least in part, account for the substance of the critique that historically UK psychiatric institutions relied upon personality disorder as a diagnosis of exclusion (NIMHE/DH 2003a)

A plea to escape the imposition of difference and otherness is found in this statement from Lucy the eponymous author of the myborderline life website (http://www.myborderlinelife.co.uk):

I would love for non-borderlines to somehow be able to taste this foreign territory from the inside.

Implicit here is the sense that Lucy is not typically responded to empathically and has perhaps herself internalised the imposition of difference that accompanies her diagnostic label. Other recipients of personality disorder diagnoses question the 
process of diagnosis and remark upon the implications of being defined in terms of negative traits (Main 2002; p.38):

Rightly or wrongly I interpreted the label as a sign that I was fundamentally flawed, that the bad parts of me far outweighed any good attributes that might also be part of my personality.

\section{Staff Discourse}

Interestingly, lay and professional accounts can intermingle, leaving open the real possibility that care staff are equally conversant in the pejorative colloquial as well as the psychiatric and psychological. For example, Barrett (1996) observed commonplace utterances in Australian inpatient units to include 'mad as cut snake'(p.149) and 'away with the birds' (p.147). Concepts of deservingness and entitlement are also redolent in many studies of staff attitudes. Feather and Johnson (2001), for instance, concluded that the personality disordered client would be blamed more for aggressive behaviour and excused less when compared with the person diagnosed with schizophrenia.

This is exaggerated in studies of staff attitudes to people admitted to high secure hospitals under the category of psychopathic disorder where care staff deployed the terminology of 'evil' in reference to the offence behaviour of such individuals ( Bowers 2002; Mason and Mercer 1998). Staff were likely to be more understanding of the behaviour and more likely to explain it in clinical terms when the protagonists were identified as being mentally ill, and, conversely, were more likely to make sense of things in moral terms when considering the same behaviour by those deemed to be personality disordered (Feather \& Johnstone 2001) 
Potential students for specific training courses on care and treatment of personality disorder are not immune from the sort of representations which we have reviewed here. It is our experience from teaching the University Certificate and the Post Graduate Certificate in Personality Disorder that students arrive at such courses already with firmly held views. We have secured written consent from previous students to include in this paper anecdotal reference to students' attitudes towards this client group as expressed in teaching and learning exercises.

It is our experience that when students' views are initially solicited they more often than not coincide with lay or moralistic beliefs, rather than being informed by professionalized or evidence-based accounts. This is a relatively unusual state of affairs in education where the learning outcomes are heavily focused on the acquisition and development of knowledge, not necessarily attitudinal changes. Where the client group is the personality disordered, however, this is turned on its head. It is the views and beliefs about the client group that can be most prominent in the student consciousness and personal opinions are likely to be freely verbalised and brought to the foreground in any learning activities. It is possible that the stigma attached to personality disorder has an effect upon the student in the same way as it does members of the public: applying moral attributions to the client group rather than value-free scientific descriptions (Pilgrim 2001). These must be negotiated and, if necessary, challenged before other course content can be adequately dealt with.

Examples of this from our experience include the sort of terminology that students use to describe individuals. Typically, the language employed defines people in terms of negative or moralistic references to behaviour. At the commencement of teaching exercises students on our courses have listed how they view people with a diagnosis of personality disorder. People are referred to as: 
Manipulating

Abusive

Bad

Dependant - clingy

Attention seeking

Difficult

Uncooperative

Saboteurs (of care and the care of others)

Unappreciative

Inconsistent

Disinhibited

Disrespectful

Unreliable - will let you down

Liars

Interestingly, whenever we have done such exercises, the terminology is exclusively negative in tone, repetitious, consistent and unmitigating. Over several years, course members have represented many different disciplines within mental health and public sector services, including nurses, social workers, criminal justice workers, occupational therapists, social therapists and doctors. Initially, the unifying factor between these groups is their ambivalence towards the person with the label 'personality disorder'. The unremitting negativity may be mediated by attempts to explain or understand problematic behaviour, yet even these examples are few and far between and participants rarely seek to include positive personal attributes or valued behaviour in such lists. Clearly many of the descriptive terms used are formally associated with available diagnostic criteria (APA 2000) and have a utility, from an objective position, in diagnosis. However, the expressed discourse is often shrouded in emotive phraseology and accompanied with audible, tonal emphasis. 
Arguably, the categorical approach to definition and diagnosis embodied within psychiatric classification systems is itself an example of the social processes of constructing difference and otherness (Castillo et al 2000; Crowe 2000, Harper 2002). Hence, it is not surprising if there is correspondence between lay and professionalized discourse in this regard. Beresford (2002: p.29) has argued that standard psychiatric diagnostic systems operate to reinforce the 'strange difference' of otherness by emphasising abnormality and biologically defined pathology; consequently the diagnosed become 'divorced from the rest of humanity'. The categories of personality disorder can function to suggest that various negative characteristics are the sole province of those diagnosed, which is palpably not the case. Given this, one service user has wondered if:

it wouldn't be worse to be diagnosed as having an 'ordered personality' ...because it seems to me that the traits that make up a personality disorder are the traits of life. (Main 2002; p.38)

In a user led study utilising emancipatory research methods, service users carrying a diagnosis of personality disorder constructed their own definitional framework, distinct from the accepted clinical taxonomies (Castillo et al 2000). This new construct moved beyond symptoms and traits to included reference to contextual factors, triggers, coping strategies and insights into effectiveness of treatments. The authors conclude that there is an 'overwhelming need for a reframing and renaming of personality disorder, to offer a better understanding of this human condition' (Castillo et al 2000; p.20).

Whilst the very real challenges which arise in the care of this client group ought not to be minimised, there would seem to be an unhelpful polarisation of 
viewpoint evidently at play. It would seem that there has been very little shift in the attitudes held by workers since the 1980's when Lewis and Appleby (1988) concluded that suicide attempts and other behaviours displayed by the personality disorder client were viewed as manipulative and under voluntary control.

\section{Training and education as deconstructive acts}

Until very recently in the UK, training and education about personality disorder was minimal, in many instances barely featured in pre-registration nursing courses and the shortcomings of such programmes are well documented (Gournay 2005). That lack of knowledge and understanding of personality disordered individuals then subsequently contributed to the exclusion of this client group from services. However, it is debatable whether there is any value in a service given by a worker who is not able to recognise the presence of personality disorder and who is not trained or resourced in appropriate care and treatment strategies. Future training initiatives are vulnerable to repeating previous shortcomings if insufficient attention is given to an appreciation of relevant social factors, not least the consequences of the social construction of difference in this client group. That the 'other' is brought into relief in juxtaposition to an equally constructed and idealised version of the self suggests that self-reflection and self-awareness might be important points of departure for learning and teaching:

If we are to challenge the populist presentation of madness and distress ... we must start each one of us with ourselves. (Beresford 2002 p29)

It is not our aim here to imply that it is only the students and not ourselves, as educators, who have a propensity for 'othering'. We are actually claiming that constructions of otherness happen more or less universally \& across cultures and 
that they serve a social and psychological purpose in defending the self. As such, we are not suggesting that anyone is immune to this, including ourselves. But we are proposing that consciousness can be raised and that such constructions can be recognised for what they are (essentially fictions) and then deconstructed. Then perhaps viewpoints can be reconstructed on more wholesome, progressive or helpful lines. It is this that we are trying to achieve in the classroom, not in opposition to the students, or even from a position of moral superiority, but rather in a partnership of learning. All of this said, it does not deny the fact that it is our experience that students typically arrive expressing the views we have described. We have merely, as objectively as possible, represented these here. This does not in our view cast the students as 'other' from ourselves; it actually suggests that they are human, like everyone else. The notion of 'otherness' is a much more fundamental ordering of things than suggesting one might have different views from somebody else.

The Department of Nursing at the University of Central Lancashire offers several courses devoted to the subject matter of personality disorder. These accredited courses meet a variety of academic standards; University Certificate to Masters Level. Beyond their academic rigour they have been designed to address the needs of staff from a variety of disciplines and pre-course competencies. Students may attend out of interest or as a direct response to Individual Performance Review by their managers and invariably see education as vital to their Personal Development Planning.

Such courses were originally rooted in collaborations with forensic services such as the DSPD project at Whitemoor Maximum Security Prison and the Personality Disorder Unit, Ashworth High Security Hospital. Presently, curriculum has widened to serve the needs of a broader audience within primary and secondary 
settings, predating the recognition of such training as a cornerstone of policy implementation aimed at tackling the exclusion of personality disordered individuals from mainstream mental health services (NIMHE/DH 2003b).

A broadening of the 'knowledge' component within course curriculum has also been matched by the recognition that training must also offer students a 'selfreflective' component. This experiential element is a prominent feature of other high quality training initiatives (Rigby \& Longford 2004) and a recognition of the unique difficulties and demands of caring for personality disordered individuals (Alhadeff 1994; Moran \& Mason 1996; Murphy \& McVey 2003; O’Brien \& Flote, 1997).

Arguably, attention to learning through self-reflection, and specifically the facilitation of self-awareness, might be a means for beginning to dismantle constructions of difference and otherness. The opportunity for students to explore their own feelings and the dynamics of encounters with clients is extremely important; especially in the context of personality disorder, a domain that is so reliant on interpersonal process (Bateman \& Tyrer 2004; Benjamin 2003; Smoyak 1985)

When students talk about problems in their relationships with this client group they often have a singular way of making sense of it. In these instances any difficulties or breakdown in communication is always understood in terms of essential attributes of the other person i.e. his/her personality disorder. This would be different from how they might understand similar issues if they arose in other interpersonal encounters, either with friends, colleagues, family or even strangers. In these alternate circumstances, communication difficulties are much more likely to be understood in terms of the current interaction between the two; allowing for a sense that fault might lie with either or both of the participants in any encounter. For instance, one might say "was it something I said?" 
The reality that any problems in relationships are co-constructed by the interaction between participants, regardless of whether this is a professionalized encounter or not, is highlighted by Pilgrim (2001). Drawing upon earlier work by Main (1957) Pilgrim points out:

The alienation between difficult clients and their frustrated therapists is not located in the client or practitioner alone but in the relationship between them. (Pilgrim 2001; p.261)

In contrast with the previously noted more forgiving stance towards individuals with mental illness diagnoses, the personality disordered are related to differently. In a context of difficult encounters, professional protection from hurt and manipulation is fore-grounded and interpersonal boundaries are privileged and rigorously adhered to. Yet, arguably, in this solidly boundaried domain, we get the worst of both worlds: This other person is always to blame for faults in our relationship yet I take this very personally, and get upset by it.

There is a huge paradox at stake here, the therapeutic use of self has been a pivotal part of nurse education for some time and nurses' own personalities, communication skills, and selfhood have been described as central to routine clinical encounters to the extent that it has been suggested that quality of care is dependant upon it (Bradley \& Edinburg 1986; Cutliffe \& Goward 2000; Travelbee 1971). Nurses and social workers might, similarly, define their roles in these terms. Self-knowledge is widely accepted as being crucial to the development of the therapeutic relationship (Livesley 2003). Ironically though, the focus is drawn to the therapist's responsibility to increase the clients' self-knowledge and the self-discovery that occurs within the 
context of the therapy. It is assumed that the therapist/worker possesses selfawareness and objectivity in their dealings with the client.

In work with personality disordered individuals large elements of the therapeutic encounter (even if it is cast in these terms) is devoted to efforts to protect oneself from the perceived malign effects of the other's personality and behaviour. The inevitable distancing and self-guarding of oneself when working with personality disordered individuals is often addressed in the discussion and delineation of interpersonal boundaries. Therapeutic boundaries, intended to define the limits and extent of the relationship are often set at a very conservative default level. Instead of proving a safe, collaborative and accepting arena for care and treatment to occur the boundaries effectively act as a protective line of separation. Hinchelwood (1999) discusses this in terms of the cold objectivity that occurs within workers who employ a scientific approach to the 'unpopular client'. Since therapeutic alliance is regarded as highly significant in treatment outcome (Livesley 2003), we need to acknowledge that this may be at the expense of the client's capacity for progress. In effect, all of this can be seen as an implicit denial of the humanness of the patient.

Recent emphasis upon notions of recovery in mental health care has similarly highlighted ideas of common humanity (Townsend \& Glasser 2003). Indeed, the very concept of 'recovery' encompasses the process whereby an individual can reclaim their self-esteem, pride, choice, dignity and meaning and requires the mental health worker to embrace people's humanity to facilitate this process, (Townsend \& Glasser 2003; p.83):

Recovery is about the whole person, identifying their strengths, instilling hope, and helping them to function at an optimal level by allowing them to take responsibility for their life. 
In reviewing the contribution of the worker in terms of their attitude towards the client in a very person-to-person way it is also important not to exclude attention to context, situation and environment. Personality disorder is frequently characterised by interactions with others and with environments thus providing situationalists such as Scarr \& McCartney (1983) with the suggestion that individuals who emerge themselves in stable environments may subsequently give the illusion of personal stability. From this perspective, personality disorder is a situational disorder; the behaviour of the client may be determined by the situation in which they find themselves and interact with. Mischel $(1968,1969)$ questioned the importance of emotional personality variables that promoted the view that people showed consistency in behaviours across different situations. His theory suggested that behaviours seemed to be more controlled by the situations people were in and the belief that people responded differently, or inconsistently, as situations changed. The complexity of such behaviour is reflected in Mischel's view that the term situationism is pejorative and his need to clarify that he believed that traits may remain stable over time (Mischel 1968, 1969).

There is, then, a plausible case that the prevailing social situation shapes the behaviour of the individual and indeed maintains the environment in which maladaptive and repetitive patterns occur, thus defining the personality disorder (Livesley 2003). Whereas we recognise that the individual affects the situation and changes the environment by his/her very presence, care workers also share responsibility for the environment experienced by the client, for instance the world of the ward or community. Do we not, therefore, need to recognise that the negative responses of personality disordered clients may arise, at least in part, from the situations, circumstances and specific encounters in which they find themselves? Furthermore, this all might be significantly influenced by an ineffective, uninformed 
and unprepared health care provision. However, these situational dimensions are relatively neglected in services which singularly focus on the individual to the exclusion of attention to context, situation, and psychosocial environment.

Students studying on the University of Central Lancashire's personality disorder courses are required to confront subjective feelings and responses within 'selfawareness' groups held within the course. These groups, demand a frank and honest approach to exploring the interactions between the client and the worker/ team in what is effectively a combination of case-discussion and consciousness raising. Originally, the groups were facilitated by a member of academic staff, but, following evaluation of the groups, it was decided to trial a self-facilitation model. A facilitation workshop prepares the members of the group and the following weekly sessions are self-facilitated adopting an approach similar to that developed by Michael Balint (1961), the pioneering Hungarian psychoanalyst. Balint's work revolves around his analysis of the doctor (as analyst) -patient relationship and what is learnt from practice. In particular Balint focuses on the constantly changing style of responses as a way of seeking expert practice as opposed to simply seeking solutions. Consequently, the Balint Group was established as a small self-help group interested in improving their relationships with their patients. There are clear differences between the groups that Balint devised and that formed by the student group in our case; not least that it is multi-agency in its constitution and also that a self -facilitation model has been adopted. The similarities, however, include the focus on the emotional responses to the client and any subjective motives which may exist and interfere with the workers' approach to the patient (Balint 1961).

A recent evaluation of the group revealed illuminating results. The group members described differing views: some initially felt somewhat exposed and fearful of the process, with others confused as to the value of this personal confrontation. 
The majority expressed some hesitancy and there were also concerns that the links with psychotherapy were somewhat uncomfortable. The process proved to be invaluable and gave the students opportunity to openly challenge their experiences, beliefs and responses to extremely difficult and demanding clients in a safe and supportive way. A unique learning process emerged from this group which assisted in deconstructing entrenched beliefs and raised insight into the reality of many worker/client interactions. We are able to report this anecdotally, and in doing so we draw upon both recollections of individual students' comments and also contributions to standard course evaluation reporting. We have not, however, conducted a formal research study of the progression of students' attitudes in relation to attending these courses.

Reconstructing personality disorder in terms of available alternative theoretical constructs can assist. Seeing personality disorder as part of human development, perhaps linked to previous psychological harm or trauma, opens up possibilities for compassion and empathy. More often than not, people don't connect in this way with the personality disorder client group. For service users the impression persists that staff in practice cannot get past the label. This is disappointing and contrary to the elements of policy that urge more inclusive services. Theories of social constructionism suggest that how we see things or make sense of any particular subject is massively influential in terms of how we will then act. This both explains the current impasse in therapy, but offers a route out of it. The deconstruction and reconstruction of what we mean by personality disorder is one possible solution.

One such deconstructive act would be a reengagement with people's common humanity, regardless of specific therapies. This would afford further justification for reliance upon what Pilgrim (2001) has referred to as consensus points 
in therapy or, previously, Shea (1991) has termed 'good bet' factors. Pilgrim's (2001) list includes the establishment and maintenance of positive working relationships, contractual strategies, and adherence to treatment model. Crucially, the therapist variables emphasised as most important and relevant to this client group include warmth, empathy and honesty, which are recognisably the cornerstones of a humanistic therapeutic interaction. Murphy and McVey (2003) working with a forensic population advocate that staff are able to 'establish emotionally intimate but boundaried relationships with difficult patients'. This is suggested in a context of appropriate and thorough training and clinical supervision, and, importantly, highly selective recruitment of staff who, amongst other things, know what to expect from this client group and choose to work with them.

Arguably, cognisance of the extent to which difference is socially constructed might allow for the potential of deconstructing our representations of personality disordered individuals and our relationship to them. This, in turn, would open up the possibility to reclaim elements of their common humanity. Such a standpoint, interestingly, would be in tune with attempts to understand the behaviour associated with personality disorder in terms of relevant contributing social and developmental factors. The processes and theory by which difference is constructed needs to be explicitly addressed in training - which to some extent requires individuals to be conversant with some relatively deep philosophical positions or for tutorial staff to be adept at translating theory into meaningful and readily appreciated language and terminology.

\section{Towards reclaiming the humanity in personality disorder}

With reference to other forms of prejudice and discrimination it is apparent that bringing together differentiated groups (people who see each other differently) and giving them a common task to perform is one route out of prejudice. In terms of 
our interest here, this could coalesce around therapy (as a goal for practice and education). For other forms of prejudice, simple exposure to people who don't live up to archetypal stereotypes can begin to dismantle fears and discrimination.

Yet, in the context of caring for individuals diagnosed with personality disorder, a too simplistic or uncritical approach to this issue might ultimately prove self-defeating. The fact that deeply held and enduring stereotypes of personality disorder, however unwholesome or inimical for therapy, can sometimes reflect real and actual experiences needs to be faced. However we care to define or make sense of it, the particular behaviour that typically leads to a personality disorder diagnosis is likely to challenge and frustrate care staff engaged in attempts at therapy. Similarly, the social construction of otherness and difference can be viewed as psychologically useful, defending individuals from recognition of unpalatable traits and tendencies, however infrequently evident, in their own personality. Both of these points make the case for developing sophisticated, supportive and durable systems of clinical supervision for practitioners.

Ultimately, however, the implication is that effective therapeutic measures must acknowledge and explicitly address the sort of social processes we have described here. Such therapy must proceed to seek a balanced appraisal of individuals' behaviour, incorporating attention to situational and interpersonal variables. Interpersonal boundaries are important, but these should be flexible enough to allow for individuals to connect in therapy and also for ordinary social discourse to take place in the context of wards or other treatment settings. Practitioner-client relationships could be improved immeasurably by attempts to arrive at a balanced view of individuals, alert to redeeming or positive features of others' personalities, rather than focusing only on the negative. This deconstruction of damaging representations and associated reclamation of the common humanity in 
our clients should be a core element of practitioner training and education. If it is not, therapeutic interventions which show promise in research studies may prove relatively useless in routine practice and the policy goal of inclusive services will not move beyond mere rhetoric.

A diagnosis of personality disorder does not mean you're not a nice person (Anonymous, cited in NIMHE, 2002). 


\section{References}

American Psychiatric Association (2000) Diagnostic and Statistical Manual of Mental Disorders (DSM-IV-TR) Washington

Anderson P (2004) Personality Disorder and Service User Involvement.

http://www.nimhenorthwest.org.uk. Accessed 17 February 2005.

Alhadeff, L. (1994). Managing difficult populations. New Directions for Mental Health Services, 63, 71-79.

Balint M \& Balint E (1961) Psychotherapeutic Techniques in Medicine New York: Lippincott

Barrett, R. (1996) The Psychiatric Team And The Social Definition Of Schizophrenia: An Anthropological Study Of Person And Illness. Cambridge: Cambridge University Press.

Bateman, A. \& Tyrer, P. (2004). Services for personality disorder: organisation for inclusion. Advances in Psychiatric Treatment, 10, 425-433.

Benjamin, L. (2003) Interpersonal Diagnosis and Treatment of Personality Disorder ( $2^{\text {nd }}$ Edition). New York: Guilford Press.

Beresford, P. (2002) Encouraging caring communities. Mental health Today, February, 28-30. 
Blackburn, R. (1988) 'On Moral Judgements And Personality Disorders: The Myth Of Psychopathic Disorder Revisited'. British Journal of Psychiatry, 153, 505-12.

Bowers, L. (2002) Dangerous and Severe Personality Disorder: Response and Role of the Psychiatric Team. London: Routledge.

Bradley J C \& Edinburg M A (1986) Communication in the Nursing Context London: Appleton \& Lange.

Canales, M. (2000) Othering: toward an understanding of difference. [vulnerability and empowerment: part 1]. Advances in Nursing Science, 22, 16-31.

Castillo, H., Allen, L. \& Warner, K. (2000) Crossing the borderline. Openmind, 106 (Nov/Dec) pp 20-21

Chiswick D (2001) Dangerous Severe Personality Disorder : From Notion to Law Pychiatric Bulletin 25, 282-283

Crowe, M. (2000) Constructing normality: a discourse analysis of the DSM-IV. Journal of Psychiatric and Mental Health Nursing, 7, 69-77.

Cutcliffe, J \& Goward P, ( 2000) Mental health nurses and qualitative research methods: a mutual attraction? Journal of Advanced Nursing 31(3) pp 590-598

Dalal, F. (2001) Insides and outsides: a review of psychoanalytic renderings of difference, racism and prejudice. Psychoanalytic Studies, 3, 1, 43-66. Department of Health (2000) Reforming the Mental Health Act London: HMSO 
Feather, N. \& Johnstone, C. (2001) Social Norms, Entitlement, and Deservingness:

Differential Reactions to Aggressive Behavior of Schizophrenic and Personality

Disorder Patients. Personality and Social Psychology Bulletin, 27, 6, 755-767.

Foucault, M. (1972) The archaeology of knowledge. (trans. By A. Sheridan Smith)

London, Tavistock Publications Ltd.

Fox, N. (1993) Postmodernism, sociology and health Buckingham, Open University Press

Geertz, C. (1977) From the Native's Point of View: On the Nature of Anthropological Understanding. In J. Dolgin, D. Kemnitzer \& D. Schneider (Eds) Symbolic Anthropology: A Reader in the Study of Symbols and Meanings. (pp. 480-492) New York: Columbia University.

Gleeson, K. (1991) Out of our minds: the deconstruction and reconstruction of madness. Unpublished PhD thesis. University of Reading.

Gournay, K (2005) The changing face of psychiatric nursing. Revisiting mental health nursing. Advances in Psychiatric Treatment, 11, 6-11

Hamilton, B. \& Manias, E. (2006) 'She's manipulative and he’s right off': A critical analysis of psychiatric nurses' oral and written language in the acute patient setting. International Journal of Mental Health Nursing, 15, 84-92.

Harper, D. (2002) The tyranny of expert language. Openmind, 113 (Jan/Feb) 8-9. 
Hinshelwood, R. (1999) The Difficult Patient. British Journal of Psychiatry, 174,187190.

Holmes, D. (2001) From iron gaze to nursing care: mental health nursing in the era of panopticism. Journal of Psychiatric and Mental Health Nursing, 8, 7-15.

Holmes, D. (2003) Constructing monsters: correctional discourse and nursing practice. International Journal of Psychiatric Nursing Research, 8, 942-962.

Hopkinson, C. (2002) My theory of the cause of personality disorder. Dialogue, 11, Summer, 4. http://www.dh.gov.uk/hspscb/visped.htm. Accessed: 11.4.05

Hyler, S, Gabbard, G. \& Schneider, I. (1991) Homicidal maniacs and narcissistic parasites: stigmatisation of mentally ill persons in the movies. Hospital and Community Psychiatry, 42, 10, 1044-1048.

Ingleby, D. (1985) Professionals as socializers: the 'psy complex'. Research in Law, Deviance and Social Control, 7, 79-109.

Johnson, J., Bottorff, J., Browne, A., Grewal, S., Hilton, B. \& Clarke, H. (2004)

Othering and being othered in the context of health care services. Health Communication, 16, 253-271.

Lewis G \& Appleby L (1988) Personality disorder: the patients psychiatrists dislike. British Journal of Psychiatry, 153, 44-49 
Livesley, W. (2003) Practical Management of Personality Disorder. New York: The Guildford Press.

Maccallum, E. (2002) Othering and psychiatric nursing. Journal of Psychiatric and Mental Health Nursing, 9, 87-94.

Main, L. (2002) This life. Mental Health Today, August, 38.

Main, T. (1957) The ailment. British Journal of Medical Psychology, 30, 129-145.

Mason, T. \& Mercer, D. (1998) Critical perspectives in forensic care: inside out. London, Macmillan.

McKeown, M., Anderson, J., Bennett, A. \& Clayton, P. (2003) Gender Politics and Secure Services For Women: Reflections on a study of staff understandings of challenging behaviour. Journal of Psychiatric and Mental Health Nursing, Special Forensic Edition, 10, 585-591

McKeown, M. \& Clancy, B. (1995) Images of Madness: Media Influence on Societal Perceptions of Mental Illness. Mental Health Nursing, 15, 2, 10-12.

McKeown, M., Hinks, M., Stowell-Smith, M., Mercer, D. \& Forster, J. (1999) Q methodology, risk training and quality management. International Journal of Health Care Quality Assurance, 12, 6, 254-266.

Milton J. (2000) A postal survey of assessment procedure in forensic settings Psychiatric Bulletin, 24, 254-257 
Mischel, W. (1968) Personality and assessment. New York, Wiley.

Mischel W (1969) Continuity and change in personality New York: Wiley

Morrall, P (200) Madness and Murder London: Whurr

Moran, T., \& Mason, T. (1996). Revisiting the nursing management of the psychopath. Journal of Psychiatric and Mental Health Nursing, 3, 189-194.

Murphy, N., \& McVey, D. (2003). The challenge of nursing personality disordered patients. British Journal of Forensic Practice, 5(1).pp:3-19

National Institute for Mental Health in England (NIMHE) (2002) Services for people with personality disorder: the thoughts of service users.

www.nimhe.org/downloads/Rex Haigh.doc. Accessed 21 October 2004.

NIMHE /Department of Health (DH)(2003a) Personality Disorder: No Longer a Diagnosis of Exclusion Leeds, NIMHE/DH.

NIMHE/DH (2003b). Breaking the Cycle of Rejection: The Personality Disorder Capabilities Framework. Leeds, NIMHE/DH.

O'Brien, L., \& Flote, J. (1997). Providing nursing care for a patient with borderline personality disorder on an acute in-patient unit: a phenomenlogical study. Australian and New Zealand Journal of Mental Health Nursing, 6, 137-147.

Parker, I.,Georgaca, E., Harper, D., McLaughlin, T. \& Stowell-Smith, M. (1995) Deconstructing psychopathology. London, Sage. 
Peternelj-Taylor, C. (2004) An exploration of othering in forensic psychiatric and correctional nursing. Canadian Journal of Nursing Research, 36, 130-146.

Pilgrim, D. (2001) Disordered personalities and disordered concepts. Journal of Mental Health, 10, 3, 253-265.

Rigby, M., \& Longford, J. (2004). Development of a multi-agency experiential training course on personality disorder. Psychiatric Bulletin, 28, 337-341.

Rose D (2005) It's a prison within a prison. A unit designed to treat the country's most dangerous men. An exclusive report from the Westgate by David Rose The Observer $20^{\text {th }}$ November 2005 p21- 29

Rose, N. (1990). Governing the Soul: the shaping of the private self. London: Routledge.

Royal College of Psychiatrists (1999) Council Report 71 : Offenders with Personality Disorder London Gaskell

Sampson, E. (1993) Celebrating the Other: A Dialogic Account of Human Nature. New York: Harvester Wheatsheaf.

Shea, M. (1991) Standardised approaches to individual psychotherapy of patients with borderline personality disorder. Hospital and Community Psychiatry, 42, 10, 1034-1038. 
Smoyak, S. (1985). Editorial: Borderline personality disorder. Journal of Psychsocial Nursing Mental Health Services, 23, (4), 5.

Stainton-Rogers, W. (1991) Explaining health and illness: an exploration of diversity. Hemel Hempstead, Harvester Wheatsheaf.

Stowell-Smith, M. \& McKeown, M. (1999a) Locating Mental Health in Black and White Men: A Q Methodological Study. Journal of Health Psychology, 4, 2, 209-223.

Stowell-Smith, M. \& McKeown, M. (1999b) Race, Psychopathy and Self: A Discourse Analytic Study. British Journal of Medical Psychology, 72, 459-470.

Timmi, S. (1996) Race and colour in internal and external reality. British Journal of Psychotherapy, 13, 183-192.

Townsend W. \& Glasser N (2003) Recovery: the heart and soul of treatment Psychiatric Rehabilitation Journal Summer 2003;27,1 pp.83-85

Travelbee (1971) Interpersonal Aspects of Nursing Philadelphia: F E Davies

Venn, C. (1984). The subject of psychology. In J. Henriques, W. Hollway, C. Urwin, C. Venn, \& V. Walkerdine (Eds) Changing the subject (pp. 119-152). New York: Muthuen.

Warner, J. \& Gabe, J. (2004) Risk and liminality in mental health social work. Health Risk and Society, 6, 387-399. 
Willig, C. (1999) [ed] Applied discourse analysis: social and psychological interventions. Buckingham, Open University Press.

World Health Organisation (1992) International Classification of Mental and Behavioural Disorders, Geneva: World Health Organisation

Young, J. (1999) The Exclusive Society. London, Sage. 